\title{
METÁFORA EN LO ALTO DE LOS CIELOS, METÁFORAS AL FONDO DE LA CALLE: \\ El uso de la metáfora en Life before man, de Margaret Atwood
}

M." Teresa Gibert Maceda

$U N E D$

Cuando llegó a mis manos la invitación para participar en unas Jornadas sobre "Imágenes del Canadá Contemporáneo", me encontraba leyendo Life Before Man, novela que - por ser un excelente ejemplo del realismo social de los años setenta- podía constituir una materia de estudio apropiada para la ocasión. Como entonces también estaba yo realizando un trabajo sobre la teoría bipolar del lenguaje de Roman Jakobson, inmediatamente pensé en aplicar dicha teoría a la cuarta novela de Margaret Atwood. Por consiguiente, en la ponencia presentada oralmente en octubre de 1989 y ahora por escrito en estas páginas, he tratado de contemplar Life Before Man desde una perspectiva que el propio Jakobson nunca llegó a poner en práctica, pero que otros investigadores han empleado con éxito en el análisis de ciertas obras literarias'.

Evitaremos entrar en las disquisiciones teóricas que desde Aristóteles (cuya autoridad ha sido contestada ${ }^{2}$ ) hasta nuestros días han dado lugar a

' David Lodge aplica el concepto en muchos de sus ensayos, especialmente en la colección The Modes of Modern Writing: Metaphor, Metonymy, and the Typology of Modern Literature. London, Edward Arnold, 1979. En cuanto a la aplicación práctica de la teoría jakobsoniana, es también digna de mención la obra de Hans Osterwalder, T. S. Eliot: Between Metaphor and Metonymy. Zürich, Francke Verlag Bern, 1978.

2 Liselotte Gumpel, Metaphor Reexamined. A Non-Aristotelian Perspective. Bloomington, Indiana, Indiana University Press, 1984, p. X. 
millares de artículos y libros sobre la metáfora ${ }^{3}$. Así pues, no tomaremos partido en las discusiones sobre las diferencias o bien la inexistencia de fronteras entre metáfora, símil y analogía ${ }^{4}$. Dejando a un lado las distinciones de carácter retórico, tendremos en mente el único punto sobre el cual quizás existe un acuerdo general: la metáfora es el resultado de una percepción intuitiva acerca de la similitud entre lo dispars.

Si consideramos que la mayor parte de nuestro sistema conceptual es de naturaleza metafórica y que manifestamos nuestra visión de la realidad tanto por el uso de las metáforas convencionales como por la creación de otras nuevas, pronto llegaremos a la conclusión de que el examen del lenguaje metafórico que habitualmente empleamos revela datos esenciales sobre nuestro pensamiento ${ }^{6}$. En consecuencia, no trataremos las metáforas como elementos de tipo puramente decorativo, sino que, trascendiendo de su carácter ornamental, las examinaremos en cuanto procesos cognoscitivos que median entre la mente humana y la cultura?

Recordemos el postulado de Jakobson según el cual cada autor revela su estilo personal y sus preferencias verbales al manejar los dos tipos de enlace generadores del discurso: la metáfora y la metonimia ${ }^{8}$. Aunque ambos procesos operan en toda conducta verbal de características normales, uno de los dos suele prevalecer; concretamente Jakobson indica que la metonimia predomina en las escuelas literarias realistas y en los escritos redactados en prosa. Sin embargo, lo más llamativo de Life Before Man - prosa realista - es precisamente lo contrario: el desarrollo del polo opuesto a la metonimia, es decir, la preponderancia del proceso metafórico. Ade-

"Buena muestra de la ingente labor en este campo son los 4.193 títulos publicados entre los años 1970 y 1985 que J. P. van Noppen compiló, continuando la empresa que iniciara Warren Shibles con su bibliografia de 1971. Warren Shibles, Metaphor: An Annotated Bibliography and History (Whitewater, Wisconsin: The Language Press, 1971). J. P. van Noppen, Metaphor. A Bibliography of Post-1970 Publications. Amsterdam \& Philadelphia, John Benjamins, 1985.

4 A pesar de que las discusiones sobre la relación entre simil y metáfora comenzaron con Aristóteles (quien consideró la metáfora como el género y el símil como la especie) y continuaron con Cicerón y Quintiliano (quienes invirtieron la relación, considerando la metáfora como especie y el símil como género), entre los autores que han tachado dicha distinción de irrelevante se halla John Middleton Murry, «Metaphor», en su Countries of the Mind (Freeport, New York, Books for Libraries Press, 1968), p. 3. Cfr. Earl R. Mac Cormac, A Cognitive Theory of Metaphor. Cambridge [Mass.] \& London, MIT Press, 1985, p. 34.

s Debe tenerse presente que ni las metáforas ni los símiles son meras comparaciones. Vid. Eva Feder Kittay, Metaphor. Its Cognitive Force and Linguistic Structure. Oxford, Clarendon Press, 1987, pp. 17-18.

- George Lakoff \& Mark Johnson, Metaphors We Live By. Chicago \& London, University of Chicago Press, 1980, p. 4.

${ }^{7}$ Earl R. Mac Cormac, op. cit., p. 2.

" Roman Jakobson, "Two Aspects of Language and Two Types of Linguistic Disturbances", en R. Jakobson \& Morris Halle (eds.), Fundamentals of Language. The Hague, Mouton, 1956, pp. 55-82. 
más, la lectura de las otras novelas de Atwood corrobora esta primera impresión y pone de manifiesto que tal preferencia por la metáfora no es un fenómeno restringido al caso de Life Before Man, sino generalizable a todas sus obras de ficción y creciente a lo largo del tiempo. Nuestra reacción inmediata al constatar este rasgo tan sobresaliente puede inducirnos a explicarlo por la condición de poeta que ostenta la escritora. En efecto, abundantes son las metáforas a través de la obra poética de Atwood, en particular durante su primera fase, si bien su poesía ulterior parece mostrar una progresiva tendencia hacia la metonimia ${ }^{9}$. Así pues, si repasamos cronológicamente los poemas de Atwood, observaremos que las relaciones metonimicas o de contigüidad van desplazando a las metafóricas o de semejanza, mientras que en sus novelas sucede a la inversa: el uso de la metáfora - presente desde el principio- se va expandiendo y perfeccionando con el paso de los años ${ }^{10}$. En realidad, esta paradoja no es más que una consecuencia lógica en una escritora que nunca deja de emplear su voz y su sensibilidad de póeta cuando escribe novelas, sin que ello reste mérito alguno a sus cualidades narrativas.

Además de tener en cuenta la influencia interna de su propia poesía, debemos pensar también en la condición de ensayista de esta autora polifacética. Margaret Atwood ha manifestado inequivocamente que es consciente de la trascendencia de los usos metafóricos, tanto por parte de ella misma como cuando provienen de los demás. Asi, por ejemplo, reaccionó con ira - a mi entender, plenamente justificada - cuando la calificaron de «Reigning Queen of Canadian Literature» porque, al advertir las implicaciones negativas de tal metáfora - visión de la literatura femenina como una colmena en la que sólo cabe una reina, que será sustituida por otra cuando se agote su capacidad reproductora-, rechazó este título como si de un insulto se tratase, añadiendo: «anyone who takes language seriously would never use such metaphor without being aware of its sinister range of meanings ${ }^{11}$.

En otra ocasión, observó con ironía lo absurdo que resulta emplear una metáfora como "she had the startled eyes of a wild bird», porque en nada se parece la mirada de un búho a la de un cuco $^{12}$. Y esta reflexión nos lleva directamente a dos de las características distintivas de las metáforas que emplea Atwood: claridad y exactitud. Ella no comete errores como el in-

9 Sherrill E. Grace, "Margaret Atwood and the Poetics of Duplicity», en Arnold E. Davidson \& Cathy N. Davidson (eds.), The Art of Margaret Atwood: Essays in Criticism. Toronto, Anansi, 1981, pp. 55-68.

${ }_{10}$ Jakobson advirtió que toda metonimia es ligeramente metafórica en «Linguistics and Poetics», en Thomas A. Sebeok (ed.), Style in Language. Cambridge (Mass.), 1960, p. 370.

"Joyce Carol Oates, "A Conversation with Margaret Atwood", Ontario Review, n." 9. Fall-Winter, 1978-1979, p. 12.

${ }_{12}$ Margaret Atwood. Murder in the Dark. London, Jonathan Cape, 1984, pp. 35-36. 
dicado, porque presta una atención meticulosa a los detalles y porque - según ella misma ha advertido recordando su temprana vocación por la pintura- desde niña ha estado "very visually oriented»" ${ }^{13}$.

El interés de Atwood por el uso de las metáforas no sólo le impulsa a reflexionar sobre ellas en entrevistas y en sus trabajos de crítica literaria, sino que le lleva a mencionarlas en sus obras de ficción e incluso llega a escribir el siguiente verso: "You don't like these metaphors»" ${ }^{14}$. Pero, aunque la autora no se refiriese explícitamente a las metáforas una o dos veces en cada una de sus novelas - con un tono bastante didáctico-, el lector captaría igualmente esta dimensión por lo evidente que resulta ${ }^{15}$. Ya los títulos de varias novelas suyas dirigen nuestra atención hacia sus símbolos centrales: el pastel con forma de mujer en The Edible Woman, las imágenes de inmersión en el agua en Surfacing, y la enfermedad o corrupción en Bodily Harm. A Margaret Atwood le gusta extenderse elaborando una metáfora o bien formar series de metáforas a lo largo de cada novela, volviendo repetidamente sobre una misma idea, insistiendo en un tipo concreto de imágenes que ella agrupa para dar énfasis a un tema determinado. En Life Before Man ese tema es la oposición entre la vida cotidiana real frente a la vida creada por la fantasía, ambos tipos de vida contrapuestos a la muerte.

Life Before Man puede someterse a varios niveles de lectura. Así, la primera, superficial, pone de manifiesto una sucesión de intrigas sentimentales, basadas en el consabido triángulo amoroso: el matrimonio formado por Elizabeth y Nate, con la frágil Lesje en el tercer extremo. La trama se complica porque el triángulo convencional (que da lugar a la estructura de la novela) presenta varias ramificaciones: Elizabeth en su momento se relacióno con Chris, Nate con Martha y, por último, Lesje con William hasta que rompe con él y se establece con Nate. Elizabeth deshace el equilibrio geométrico merced a su experiencia erótica con William, una vez que ambos han sido abandonados por sus respectivos cónyuges y se ven convertidos en sendos "premios de consolación" (p. 212).

A pesar de los frecuentes cambios de pareja, la vida transcurre monótonamente. El suicidio de Chris, motivado por el rechazo de Elizabeth, es el único acontecimiento digno de ser recordado. Todo lo demás es aburrido y banal. Esta persistente trivialización de los acontecimientos que tradicio-

13 J. R. Struthers, "An Interview with Margaret Atwood», Essays on Canadian Writing, 6, Spring, 1977, p. 20.

${ }_{14}$ Margaret Atwood, You Are Happy. Toronto, OUP, 1974, p. 27.

is Ya en su primera novela, The Edible Woman (London: Virago, 1989; 1." ed., 1969), Atwood se refiere a las metáforas que emplea Clara al hablar de los hijos (p. 36) y presenta a Fischer escribiendo un ensayo sobre "Malthus and Creative Metaphor» (p. 197). En Life Before Man (London, Virago, 1986; 1." ed., 1979), Nate se extraña ante una metáfora que emplea Martha (p. 34) y más adelante piensa que su madre habla metafóricamente cuando alude a sus pasados deseos de suicidio (p. 286). 
nalmente han idealizado los escritores queda acentuada por el uso sistemático de metáforas extraídas de lo cotidiano. Por ejemplo, Elizabeth piensa que se casó con Nate con la misma facilidad con que alguien se prueba un zapato (p. 23) ${ }^{16}$. Otros símiles hacen referencia al matrimonio como transacción comercial (p. 183), como tema de conversación durante la cena (p. 192), como la caza de una mosca por parte de una araña (p. 119), como ratonera (p. 162), como red (p. 258) y como trampa para pescar langostas usando la carne a modo de cebo (p. 259).

Quizá no resulte extraño que la relación conyugal sufra semejante tratamiento y podriamos suponer que, por el contrario, las relaciones extramaritales suscitarian grandes pasiones. Pero tampoco ocurre así. El joven con el que Elizabeth llevó a cabo su primera experiencia sexual completa, al acabar, le pidió disculpas como si le hubiera pisado un pie o hubiera estornudado (p. 179). Cuando Elizabeth hizo el amor por primera vez con Chris, decidió que nunca rebajaría sus aspiraciones, como si se tratara de un regateo (p. 74). Cuando Martha, ex-amante de Nate, se entrevista con la esposa de éste, se queja del marido como si fuese de un niño que hubiera roto una ventana con un balón de béisbol y Elizabeth fuera la madre del pequeño recibiendo la reclamación (p. 147).

En este contexto no sorprende que tales relaciones carezcan de emoción. Así, Elizabeth recuerda la suya con William como algo no desagradable, pero tampoco memorable: algo asi como dormir con una porción - grande y bastante activa - de queso de Philadelphia (p. 213). Y aquí encontramos precisamente uno de los ejemplos de un procedimiento usual en Atwood consistente en jugar con una metáfora, extrayendo todas sus consecuencias, rechazando los aspectos que le disgustan y sustituyéndola al final por otras más apropiadas, que completan o bien contrarrestan a las anteriores. Elizabeth no queda contenta con la metáfora del queso, porque el lector puede pensar que William carece de misterio, cuando en realidad es tan misterioso como una botella, una manzana o cualquier otro objeto del universo. Además, tampoco es totalmente blando como un queso cremoso, porque alberga cierta energía e incluso violencia. Por eso, quizás inspirada por la expresión idiomática inglesa «full of beans», Elizabeth imagina unos fréjoles mejicanos que saltan en una caja con algodón. Pero a Elizabeth no le gusta abrir cajas cuyo contenido adivina. ¿Por qué va a molestarse en abrir a William si no reserva sorpresa alguna? Entonces, por contraste, viene a la mente de Elizabeth el recuerdo de Chris: un pais peligroso, lleno de emboscadas y guerrillas, el centro de un torbellino. Por último, todo este proceso razonador

${ }^{16}$ En The Handmaid's Tale Offred recuerda la época en que hombres y mujeres se probaban unos a otros, como si fueran trajes, hasta que encontraban uno que les sentara bien. Margaret Atwood, The Handmaid's Tale. London, Virago, 1987; 1." ed., 1985, p. 61. 
concluye con un pensamiento; a cierta edad se comprende que el amante maràvilloso de una mujer puede resultar para otra un zapato gastado.

Insatisfecha con William, Elizabeth busca sensaciones más fuertes con otro hombre, pero esa escapada tampoco surte los efectos esperados. Lo que pertenece al mundo de la fantasía se evoca aquí con términos bellos y lo que ocurre realmente se describe con imágenes o vulgares o sórdidas. Elizabeth comienza por tomar una copa de un trago - como una medicina (p. 227)-con la esperanza de sentir inmediatamente el deseo igual que una flor surge en el desierto. Pero las flores existen sólo en su imaginación; lo cierto es que su cuerpo según está sentada en el bar parece un saco de arena: pesado, seco, inanimado. Poco después experimentará repulsión cuando la mano del hombre suba por sus piernas al igual que una araña (p. 229) y llegará a la conclusión de que ha sido víctima de una broma, como si al abrir un paquete hubiera saltado una serpiente con resorte (p. 229).

Comparada con Elizabeth, Lesje tiene una visión diferente de los encuentros sexuales y, en consecuencia, se expresa con otro tipo de símiles. Ella desearía hacer el amor con dos empleados del museo donde trabaja, como si fuera un ejercicio saludable, consistente en nadar o correr dando una vuelta a la manzana (p. 221). Cuando Lesje imagina a William tratando de tener hijos con una mujer de su misma clase social, los compara a ambos con dos salmones realizando el proceso de fertilización a distancia, sin tocarse (p. 29).

En estrecha relación con este tema está la forma en que los distintos personajes perciben la maternidad. Elizabeth está obsesionada con el símbolo del árbol que hinca las raíces en la tierra al igual que un niño muerde el pecho de su madre (pp. 59-60 y 250). Esta imagen agresiva se completa con la percepción que tiene Elizabeth del árbol como un calamar cuyos tentáculos se adhieren para chupar vorazmente (p. 60). La idea nos recuerda The Edible Woman, novela en la que los hijos se asemejan a pulpos, sanguijuelas, percebes, lapas y varios tipos de parásitos (pp. 31, 36 y 114). Por su parte, Lesje teme que el hijo que ha concebido en un momento de rabia sea un reptil o un monstruo con escamas y un cuerno en el hocico (p. 293), pensamientos quizá sugeridos por las explicaciones de William acerca de los efectos de la contaminación sobre las embarazadas, que pueden dar a luz una masa de carne como un pomelo o una especie de platija con los dos ojos en un mismo lado (p. 142) ${ }^{17}$.

La perspectiva de Nate en cuanto padre carece de los temores que expresan las dos mujeres. Él se refiere al nacimiento de su primera hija comparándolo con un terremoto, una inundación o un tornado que ocurrió en el paritorio donde no le fue permitida la entrada (p. 164) y describe a la

1 El tema es recurrente en las novelas de Atwood. Cfr. el embarazo de Clara en The Edible Woman, pp. 31 y 114; y los temores de las Criadas en The Handmaid's Tale, pp. 122-123. 
niña recién nacida como una salchicha en hojaldre (p. 165). Al sentirse excluido, Nate se pregunta si su mujer estará convencida de haber engendrado a las niñas por partenogénesis, y él mismo confiesa que hubiera deseado sacarlas de su propia frente, para que así fuesen sólo suyas (pp. 83-84). Ahora bien, tanto él como su esposa, cuando consideran a las dos hijas ante la inminente separación y el posible divorcio, recurren al lenguaje convencionalmente empleado en tales circunstancias, según el cual se suele designar a los hijos como armas con las que los cónyuges se atacan mutuamente (pp. 84 y 256), rehenes que uno de los dos intenta conservar (p. 166) y fichas de juego (p. 204). También Lesje en su infancia se vio sometida a la persistente rivalidad entre sus dos abuelas, quienes se disputaban a la nieta como si fuera un vestido en unas rebajas (p. 93).

Otra importante serie de metáforas en Life Before Man asemeja a las personas con muñecos ${ }^{18}$. Por ejemplo, Elizabeth considera que Chris se ha suicidado estúpidamente, por una rabieta infantil tras la cual su cabeza quedó como la de un muñeco hecho pedazos (p. 11). En algún momento Lesje pensó que William tenía los ojos de una muñeca del Cáucaso o de un maniqui (p. 295). El director de la organización benéfica a la que se incorpora Nate le sonríe a la manera de una hucha con rostro de payaso (p. 305). De todos los personajes de la novela, es Nate quien de una manera más persistente es equiparado a un muñeco. Se siente como un hombre de palo (p. 105), como un muñeco de madera formado por anillos que él mismo -artesano fabricante de juguetes- construyó, haciendo que al enroscar la cabeza todas las piezas quedasen sujetas (p. 244). En dos ocasiones se identifica con el hombre de lata y corazón de serrín que aparece en El Mago de $O z$ (pp. 246 y 314). Cuando el médico le sugiere usar un taconcito para equilibrar una leve diferencia de longitud entre sus dos piernas, rehúsa sumarse a los hombres de lata con dientes postizos, ojos de cristal o zapatos ortopédicos (p. 48). Por último, al pensar que él está lejos del ideal de hijo que su madre hubiera deseado, Nate siente un maniquí de escayola dentro de su pecho, que amenaza con asfixiarlo (p. 285).

Por el contrario, el aire majestuoso de Elizabeth impide que se la compare con una muñeca. Más bien parece una estatua (p. 46) o un icono, según Lesje (p. 309); una imagen de la Virgen en un santuario, según Nate (p. 49), y ella misma desearía tener la apariencia tranquila y serena de un Buda de piedra que hay en el museo (p. 260). Tampoco a la tía de Elizabeth se la

18 En una ocasión Margaret Atwood recomendó a una escritora novel que utilizase figuras recortables de papel para imaginar mejor a sus personajes, según ella misma contó a Betsy Draine, "An Interview with Margaret Atwood", en L. S. Dembo (ed.), Interview's u'ith Contemporary Writers. Second Series, 1972-1982. Madison, Wisconsin University Press, 1983, p. 368. Este recurso puede relacionarse con el persistente tratamiento de los caracteres de las novelas de Atwood como muñecos. 
compara nunca con una muñeca, sino, al igual que a su sobrina, con una estatua (p. 281). En cambio, la debilidad de Lesje permite asimilarla no sólo a una muñeca (p. 168), sino también a una niña (pp. 168, 240, 264).

Cuando Atwood emplea símiles para describir a sus personajes es siempre coherente, porque o bien intensifica una determinada imagen de cada uno acumulando metáforas complementarias o bien se sirve de analogías que nos comunican nitidamente las transformaciones que sufren en su personalidad a lo largo de la novela. Por ejemplo, todo lo que se dice en torno a Chris sugiere violencia: cuando Elizabeth lo abandonó, le salieron verdugones oscuros bajo los ojos como si le hubieran golpeado la cara con un cinturón (p. 234); Nate temió que atacaria a Elizabeth como un alce en celo (p. 236), pero, ante la energía con la cual la mujer lo rechazó, su cara reaccionó como el agua golpeada por una roca y acabó retirándose como un soldado extraviado de un ejército vencido (p. 236); tras el suicidio, su espiritu sigue presente como el aire antes de una tormenta (p. 23) y su cadáver es para Elizabeth como un pierna amputada (p. 11).

En contraste con la fuerza de Chris, todo en Nate sugiere una debilidad que se pone de manifiesto mediante metáforas a través de las cuales aparece como un caramelo derritiéndose (p. 32), un pedazo de masilla moldeado sucesivamente por distintas mujeres (p. 41), un deficiente mental (p. 49), un peatón imprudente (p. 163), un vendedor a domicilio o un encuestador del censo (p. 164), un ratón víctima del cepo del matrimonio o un topo hocicando en la oscuridad (p. 162), un insecto semi-ciego (p. 197), un concierto benéfico o una venta de prendas usadas (p. 210), un pequeño excremento canino (p. 258) y, por último, como el hijo pródigo (p. 305). En definitiva, Nate está muy lejos de constituir el espléndido "regalo de Dios» que su nombre significa (pp. 50 y 116).

De los tres personajes principales, es Elizabeth quien con mayor frecuencia emplea metáforas para describirse a si misma y a quienes la rodean. Algunas veces sigue un proceso mental de asociaciones verbales, como, por ejemplo, la que inicia la novela y por la cual comienza identificándose con un caracol sin concha y acaba haciéndolo con un impermeable (p. 11). La más interesante de estas asociaciones verbales es la que realiza sobre «mummy», «mum» y "mama», cadena que le hace verse como una momia, recordar su papel de madre y sentirse como la mama de la que los hijos extraen leche al igual que el árbol sacaba la savia de la tierra (p. 250). Elizabeth - que suele quedar sumida en profundas meditaciones - se siente albúmina de huevo (p. 12), humo (p. 12) y reloj de arena (p. 89), sucesivamente $^{19}$.

19 El reloj de arena, además de aludir al paso del tiempo por su cuerpo, indica la personalidad dividida de Elizabeth, según Nora Foster Stovel, «Reflections on Mirror Images: Dou- 
El lenguaje metafórico de Elizabeth adquiere connotaciones negativas cuando ella deja de percibirse a sí misma para pasar a aplicarlo a los demás, especialmente a su tía Muriel, quien es objeto de los símiles más ofensivos de toda la novela: araña (p. 119), mamut o mastodonte (p. 120), raíces retorcidas y enfermas (p. 121), crecimiento verrugoso (p. 277), encarnación del mal semejante a Hitler (p. 279) y viejo reptil (p. 297). El odio que Elizabeth ha ido acumulando desde niña contra Auntie Muriel le impulsó a identificarla con la Bruja Mala del Oeste en El Mago de Oz (p. 139). Si la pequeña Elizabeth deseaba hallar la palabra mágica con la cual disolver el cuerpo de su tía como si fuera azúcar quemado (p. 218), la Elizabeth adulta comprueba que el cáncer convierte su deseo infantil en realidad (p. 279).

El cuento El Mago de $\mathrm{Oz}$ no sólo constituye una fuente de inspiración para los símiles de Elizabeth -quien, por oposición a la Bruja Mala, identificó a su madre con Glinda la Buena (p. 139) - , sino también para la analogía de Nate con el hombre de lata a la que nos hemos referido anteriormente. Otros cuentos infantiles, como Alicia en el Pais de las Maravillas, y algunas películas también originan la mitología particular de los protagonistas y les sugieren metáforas vulgares o popularizadas ${ }^{20}$. Por ejemplo, Nate quisiera convertirse en Superman cuando entra en las cabinas telefónicas (p. 35) o en Spiderman para subir por la pared de la casa de Lesje (p. 72). Estos deseos de transformación de uno mismo o de los otros son recurrentes a lo largo de una novela en la que nadie está satisfecho con su propia personalidad y, menos aún, con la de los demás. A través de tales cambios, la realidad unas veces queda embellecida o idealizada y otras ennegrecida o deteriorada. Así, cuando Nate se enamora de Lesje, la imagina como una planta exótica cubierta de flores de azahar (p. 71); en cambio, cuando se irrita contra Elizabeth, disfruta imaginándola convertida en una esponja gigante, un gran budín de vainilla y una dentadura postiza de mamut (p. 258). Este juego infantil de Nate tiene su equivalente en las elucubraciones de Lesje, quien, acostumbrada a clasificar animales en sus trabajos de paleontología, se entretiene catalogando a Elizabeth como tiburón, sapo y cefalópodo sucesivamente (p. 265).

Las metamorfosis, en estrecha relación con las metáforas, están presentes en Life Before Man, al igual que en las demás obras de Margaret Atwood. Habiendo sido su padre entomólogo, ella pudo desde niña observar las llamativas metamorfosis de ciertos insectos que en un breve espacio de

bles and Identity in the Novels of Margaret Atwood", en Essays in Canadian Writing, 33, Fall, 1986 , p. 61 .

30 Como prueba del interés de Atwood por Alice in Wonderland, anterior a la identificación de Lesje con Alice en Life Before Man, véase The Edible Woman, ibid., pp. 193-194 y 197-200. Sobre el uso que hace Atwood de los cuentos de hadas - mitos contemporáneos- como material para sus obras, véase Linda Sandler, "Preface», Margaret Atwood. A Symposium, Malahat Review, 41 (January 1977), p. 6. 
tiempo pasan del huevo a la larva y de ésta al animal adulto ${ }^{21}$. Atwood evidencia un interés particular por estas y otras muchas transformaciones que se dan en la naturaleza, eliminando las barreras entre los reinos animal, vegetal y mineral, como sucede en el caso de los fósiles. Esta decidida preferencia por las metáforas «naturales» distingue a Margaret Atwood de muchos escritores contemporáneos, en cuyas obras se multiplican unas metáforas mecánicas que ella sólo emplea esporádicamente (por ejemplo, Lesje imagina a Elizabeth como una aspiradora en la página 245). Curiosamente, el hecho de que la acción de Life Before Man se desarrolle en el centro de Toronto no impide que la flora y la fauna sean la principal fuente de metáforas de la novela ${ }^{22}$. Este rasgo, consecuencia directa del gusto personal de la escritora, resulta adecuado en Life Before Man, porque en esta novela los personajes se evaden soñando con la naturaleza salvaje - la selva amazónica donde Nate se cree el victorioso protagonista de arriesgadas aventuras, o el paisaje prehistórico por el que pasea Lesje en medio de los dinosaurios-, y quizá también por la importancia que aquí tiene el museo, el "depósito de cadáveres» (p. 64) donde los vestigios de vida se han convertido en piezas inertes que nos recuerdan la fugacidad de la existencia en la tierra. El elevado número de metáforas cuyo origen está en el sentido de la vista, frente a las pocas que hacen referencia al del oído, ha de relacionarse con el desarrollo de la capacidad visual de la autora ${ }^{23}$. Además, el interés de Atwood por las diferentes formas en que cada individuo percibe e interpreta una misma realidad se traduce en perspectivas distintas, que dan lugar a lenguajes metafóricos coincidentes o divergentes.

Tanto a través de la creación de metáforas originales como mediante la nunca arbitraria elección de las convencionales o lexicalizadas -que a menudo examina minuciosamente e incluso reelabora- Margaret Atwood comunica con claridad y exactitud aquello que es dificil de explicar, y al mismo tiempo enriquece la prosa de Life Before Man con una gran variedad de imágenes que sugieren el tedio de lo cotidiano frente al encanto de la fantasía, aunque en algún caso ésta sólo esté poblada por los héroes de la televisión. p. 75 .

21 Bonnie Lyons, "An Interview with Margaret Atwood», Shenandoah. XXXVII, 2 (1987),

${ }^{22}$ Además de los animales que ya hemos mencionado, en Life Before Man los distintos personajes son metafóricamente comparados con los siguientes: rata (p. 35), mono (71, 274, 285), perro $(114,143)$, luciérnaga (143), jirafa (161), pája ro (208), tortuga (274), perro pequinés (279), gato (280) y becerro (300). También aparecen metáforas referidas a los siguientes elementos vegetales: las algas (34), las flores (36), los líquenes (62), las uvas pasas (105) y una parcela plantada de flores $(300)$. En cuanto al reino mineral, los similes incluyen: un canto rodado (64), una losa (159), grava (119), una piedra (208) y una roca (209).

${ }^{23}$ Con esta observación constatamos un resultado estadistico. Como ejemplo de acertada metáfora relativa al sonido, puede citarse la comparación del ruido que hacen los molinillos de plástico con el que producirían las alas de unos pájaros secos (p. 73). 